\title{
Erratum to: Distinguishing perceptual and conceptual levels of recognition at group boundaries
}

\author{
Tamra C. Mendelson ${ }^{1}$
}

Published online: 23 April 2015

(C) Springer International Publishing Switzerland 2015

\section{Erratum to: Evol Ecol (2015) 29:205-215 \\ DOI 10.1007/s10682-014-9748-1}

Unfortunately, in the original publication, a reference and its citation were incorrectly published. The correct reference citation should read as "Espinosa and Paz-y-Miño-C (2014)" in page no. 2, last paragraph and page no. 6, third and fourth paragraph. The corrected reference is given below.

Espinosa A, Paz-y-Miño-C G (2014) Evidence of taxa-, clone-, and kin-discrimination in protists: ecological and evolutionary implications. Evol Ecol 28(6):1019-1029

The online version of the original article can be found under doi:10.1007/s10682-014-9748-1.

Tamra C. Mendelson

tamram@umbc.edu

1 Department of Biological Sciences, University of Maryland Baltimore County, 1000 Hilltop Circle, Baltimore, MD 21250, USA 